\title{
The roles of lipids and nucleic acids in HIV-1 assembly
}

\section{Ayna Alfadhli* and Eric Barklis*}

Department of Molecular Microbiology and Immunology, Oregon Health \& Sciences University, Portland, OR, USA

\section{Edited by:}

Jamil S. Saad, University of Alabama at Birmingham, USA

\section{Reviewed by:}

Alan Rein, National Cancer Institute, USA

Leslie Parent, Penn State College of Medicine, USA

\section{${ }^{*}$ Correspondence:}

Ayna Alfadhli and Eric Barklis, Department of Molecular

Microbiology and Immunology, Oregon Health \& Sciences University, 3181 SW Sam Jackson Park Road, Portland, OR 97239, USA

e-mail: alfadhli@ohsu.edu; barklis@ohsu.edu
During HIV-1 assembly, precursor Gag (PrGag) proteins are delivered to plasma membrane (PM) assembly sites, where they are triggered to oligomerize and bud from cells as immature virus particles. The delivery and triggering processes are coordinated by the PrGag matrix (MA) and nucleocapsid (NC) domains. Targeting of PrGag proteins to membranes enriched in cholesterol and phosphatidylinositol-4,5-bisphosphate (PI[4,5]P2) is mediated by the MA domain, which also has been shown to bind both RNA and DNA. Evidence suggests that the nucleic-acid-binding function of MA serves to inhibit PrGag binding to inappropriate intracellular membranes, prior to delivery to the PM. At the PM, MA domains putatively trade RNA ligands for PI $(4,5) \mathrm{P} 2$ ligands, fostering high-affinity membrane binding. Triggering of oligomerization, budding, and virus particle release results when NC domains on adjacent PrGag proteins bind to viral RNA, leading to capsid (CA) domain oligomerization. This process leads to the assembly of immature virus shells in which hexamers of membrane-bound MA trimers appear to organize above interlinked CA hexamers. Here, we review the functions of retroviral MA proteins, with an emphasis on the nucleic-acid-binding capability of the HIV-1 MA protein, and its effects on membrane binding.

Keywords: matrix, RNA, PI(4.5)P2, lipid, Gag

\section{INTRODUCTION FUNCTIONS OF RETROVIRAL MA PROTEINS}

Retroviruses such as the human immunodeficiency virus (HIV) are membrane-enveloped viruses that bud from the plasma membranes of infected host cells (Coffin et al., 1997; Swanstrom and Wills, 1997; Freed, 1998; Goff, 2001). Retroviral genomes encode PrGag polyproteins that are necessary and sufficient for assembly and release of virus-like particles (VLP) from cells (Campbell and Vogt, 1995; Coffin et al., 1997; Swanstrom and Wills, 1997; Campbell and Rein, 1999; Gross et al., 2000; Campbell et al., 2001). The HIV-1 precursor Gag protein (PrGag) initially is synthesized on cytosolic ribosomes and becomes cotranslationally modified by the $\mathrm{N}$-terminal attachment of a myristoyl group by $\mathrm{N}$-myristoyltransferase (Mervis et al., 1988; Bryant and Ratner, 1990; Ono and Freed, 1999, 2001; Morikawa et al., 2000; Ono et al., 2000; Tritel and Resh, 2000; Resh, 2004), although myristoylation is not universal among retroviral PrGag proteins (Erdie and Wills, 1990; Provitera et al., 2000; Dalton et al., 2005). PrGag proteins associate with the inner layer of the plasma membrane (PM), where they oligomerize, assemble, and bud off from cells as immature virions. The assembly process of retroviruses appears to be triggered by the association of PrGag proteins with viral RNA (vRNA) at the plasma membrane (Rein, 1994; Spearman et al., 1994; Muriaux et al., 2001; Jouvenet et al., 2006, 2008; Ott et al., 2009). However, several retroviruses, such as mouse mammary tumor virus (MMTV) and the Mason-Pfizer monkey virus (MPMV), assemble within the cytoplasm before being transported to cell membrane (Choi et al., 1999; Stansell et al., 2007). During the maturation process, cleavage of HIV-1 PrGag by the viral protease (PR) generates the mature myristoylated matrix (MA) protein as well as capsid (CA), nucleocapsid (NC), p6 and two spacer peptides, Sp1 and Sp2 (Swanstrom and Wills, 1997; Freed, 1998).

The MA domain plays multiple roles in the viral replication cycle. One of these roles involves the incorporation of the viral envelope (Env) proteins into virus particles. Evidence indicates that HIV-1 MA interacts with the cytoplasmic tail (CT) of gp41, the transmembrane (TM) portion of the HIV-1 Env protein, to facilitate the incorporation of Env proteins into assembling virions (Yu et al., 1992; Dorfman et al., 1994; Freed and Martin, 1995, 1996; Wyma et al., 2000; Davis et al., 2006; Checkley et al., 2011). Several models have been proposed to explain the incorporation of retroviral Env protein into virus particles (reviewed by Checkley et al., 2011). One of these models is the passive model, in which membrane proteins at assembly sites are incorporated into virions as innocent bystanders. This model was based on the observation that retroviruses could incorporate foreign membrane proteins into their envelopes. When glycoproteins from heterologous viruses are assembled into a retrovirus envelope, the process is termed pseudotyping (Zavada, 1982; Lusso et al., 1990; Arthur et al., 1992; Ott, 2008; Checkley et al., 2011). For example, infectious HIV-1 particles can be produced with foreign glycoproteins such as the vesicular stomatitis virus G protein (VSV-G; Cronin et al., 2005; Checkley et al., 2011) or amphotropic murine leukemia virus (MLV) Env (Lusso et al., 1990; Wang et al., 1993). In these cases, HIV-1 cores and genomes are delivered to target cells carrying the VSV or MLV receptors (Jorgenson et al., 2009). The passive model also is supported by the finding that removal of most of HIV-1 gp41 CT has a moderate effect on Env glycoprotein incorporation into HIV-1 particles (Wilk et al., 1992; Freed and Martin, 1995, 1996; Akari et al., 2000; Murakami and Freed, 2000). 
Although the passive model is consistent with observations for a number of retroviruses (Landau etal., 1991; Reiser et al., 1996; Lewis et al., 2001; Liu et al., 2004; Jorgenson et al., 2009), several lines of evidence suggest an interaction between MA and Env. For HIV-1, it has been reported that mutations in MA may decrease levels of HIV-1 Env incorporation into virions (Wang et al., 1993; Freed and Martin, 1995, 1996; Reil et al., 1998). Moreover, some mutations in MA (Freed and Martin, 1995, 1996; Reil et al., 1998) have been shown to mitigate the effects of certain Env mutations. Interestingly, for some but not all cell types, MA mutations can be compensated via full deletions of the HIV-1 Env protein cytoplasmic tail (CT; Freed and Martin, 1995, 1996; Checkley et al., 2011). These results suggest that while truncated HIV-1 Env can be incorporated passively into virions in some cell types, full-length Env requires an interaction with MA for assembly into virions (Freed and Martin, 1995, 1996; Checkley et al., 2011). Data from other experiments indicate that MA domains in immature PrGag lattices lock Env proteins into a non-fusogenic state, and that PrGag processing serves as a switch to regulate envelope protein function (Murakami et al., 2004; Wyma et al., 2004; Jiang and Aiken, 2007). In vitro studies have shown direct binding between MA and the CT Env in several biochemical experiments for both HIV-1 and Simian immunodeficiency virus (SIV; Cosson, 1996; Wyma et al., 2000; Manrique et al., 2008). Consistent with these observations, structural studies have shown that HIV-1 MA proteins assemble lattices on phosphatidylinositol-(4,5)-bisphosphate (PI[4,5]P2) membranes in which residues implicated in CT binding point toward lattice holes (Yu etal., 1992; Dorfman etal., 1994; Freed and Martin, 1996; Ono etal., 1997; Murakami and Freed, 2000; Davis etal., 2006; Bhatia et al., 2007; Alfadhli etal., 2009a; Checkley et al., 2011; Tedbury et al., 2013). Given this membrane organization of MA, it seems likely that membrane proteins with short cytoplasmic domains may enter Gag lattices passively, whereas proteins such as HIV-1 Env, with long cytoplasmic tails require MA interactions.

Implicit in the data described above is the assumption that MA binds to membranes, and another essential function of MA is to target PrGag proteins to their lipid raft assembly sites at the PMs of infected cells (Ehrlich et al., 1996; Spearman et al., 1997; Scarlata et al., 1998; Bouamr et al., 2003; Murray et al., 2005; Jouvenet et al., 2006; Bhatia et al., 2007; Dalton et al., 2007; Scholz et al., 2008; Hamard-Peron and Muriaux, 2011). In most mammalian retroviruses, membrane targeting is dependent on two structural features present on MA: the N-terminal myristyl group and a group of basic residues. For such viruses, the $\mathrm{N}$-terminal myristyl group functions in concert with a group of conserved basic residues to promote membrane binding (Zhou et al., 1994; Tang et al., 2004; Saad et al., 2008). However, Gag proteins of some retroviruses, such as Rous sarcoma virus (RSV) and equine infectious anemia virus (EIAV), lack the myristate anchor, and Gag targeting and binding to the PM is mainly mediated by electrostatic interactions (Erdie and Wills, 1990; Parent et al., 1996; Callahan and Wills, 2000; Provitera et al., 2000; Dalton et al., 2005). Compelling evidence favors the idea that HIV assembly does not occur just anywhere at the PM, but at lipid rafts and at PI(4,5)P2enriched areas (Ono et al., 2004; Chukkapalli et al., 2008, 2010;
Chukkapalli and Ono, 2011). MA-PI(4,5)P2 interactions also have been observed for MLV, MPMV, and EIAV (Stansell et al., 2007; Chan et al., 2008; Chen et al., 2008; Hamard-Peron et al., 2010). In cell culture, decreasing the levels of cellular PI $(4,5) \mathrm{P} 2$ by overexpression of polyphosphoinositide 5-phosphatase IV was shown to reduce HIV-1 and MLV assembly efficiency, resulting in the delivery of viral proteins to intracellular compartments (Ono et al., 2004; Chan et al., 2008; Chukkapalli et al., 2008; Hamard-Peron et al., 2010; Inlora et al., 2011). In contrast, recent studies have shown that human T-lymphotropic virus type 1 (HTLV-1) Gag is markedly less dependent on $\mathrm{PI}(4,5) \mathrm{P} 2$ for membrane binding and particle release than HIV-1 Gag (Inlora et al., 2011). For RSV, Chan et al. (2011) reported that RSV Gag bound effectively to a variety of phosphorylated phosphatidylinositols, and that reduction of cellular PI(4,5)P2 and PI(3,4,5)P3 levels did not reduce Gag PM binding or virus particle release. However, more recently, Nadaraia-Hoke et al. (2013) reported that depletion of cellular PI $(4,5) \mathrm{P} 2$ and PI $(3,4,5) \mathrm{P} 3$ yielded reductions of both RSV Gag PM binding and virus particle release. Interestingly, RSV Gag mutants that are impaired in nuclear trafficking were less sensitive to these effects, suggesting a link between RSV Gag PM targeting and nuclear trafficking (Nadaraia-Hoke et al., 2013).

In addition to Env protein and membrane binding, several reports have implicated nucleic acid binding properties to retroviral MAs. These viruses are HIV-1 (Luban and Goff, 1991; Bukrinsky et al., 1993; Von Schwedler et al., 1994;; Lochrie et al., 1997; Miller et al., 1997; Reil et al., 1998; Haffar et al., 2000; Purohit et al., 2001; Ott et al., 2005; Hearps et al., 2008; Alfadhli et al., 2009b, 2011; Cai et al., 2010; Chukkapalli et al., 2010, 2013; Monde et al., 2011), RSV (Leis et al., 1978, 1980; Steeg and Vogt, 1990), and BLV (Mansky et al., 1995; Mansky and Wisniewski, 1998; Mansky and Gajary, 2002; Wang et al., 2003). While the NC domains of retroviral PrGag proteins are essential for viral RNA (vRNA) encapsidation, experiments have shown that MA proteins may also possess binding functions and can substitute for the HIV-1 NC protein assembly function (Ott et al., 2005). [However, deletion of the NC domain dramatically reduces the assembly of MLV particles (Muriaux et al., 2004)]. It has been conjectured that such MA-nucleic acid binding might facilitate PrGag delivery to the $\mathrm{PM}$, virus assembly, and/or nuclear import of viral preintegration complexes (PICs) (Bukrinsky etal., 1993; Von Schwedler et al., 1994; Miller et al., 1997; Reil et al., 1998; Haffar et al., 2000; Hearps et al., 2008; Cai et al., 2010). In this review, we focus on the role of MA binding to RNA and summarize the importance of Gag MA interactions with RNA for HIV and other retroviruses, with the hope that this comparative approach can shed more light on our understanding of the importance of this function and ways of inhibiting that role.

\section{STRUCTURAL ASPECTS OF RETROVIRAL MATRIX PROTEINS}

Matrix structures for the following retroviruses have been determined: HIV- 1 (Massiah et al., 1994; Hill et al., 1996; Tang et al., 2004; Saad et al., 2006, 2007), HIV-2 (Saad et al., 2008), SIV (Rao et al., 1995), human T-lymphotropic virus 2 (HTLV-2; Christensen et al., 1996), BLV (Matthews et al., 1996), M-PMV (Conte et al., 1997), Rous sarcoma virus (RSV; N-terminal fragment; McDonnell et al., 1998), EIAV (Hatanaka et al., 2002), and MLV 
(Riffel et al., 2002). In contrast to their low sequence homology, structures of retroviral MA proteins are remarkably similar (Figure 1; Murray et al., 2005). They all share a globular core composed of $\alpha$ helices. The N-termini of the MA proteins tend to contain basic residues that appear to foster interactions of MA with acidic phospholipid head groups. Another essential element that contributes to membrane binding is the myristyl group found in most retroviral MAs, including HIV-1 (Gottlinger et al., 1989; Bryant and Ratner, 1990; Spearman etal., 1994), HIV2 (Saad etal., 2008), MLV (Henderson et al., 1983), M-PMV (Schultz and Oroszlan, 1983), and HTLV (Ootsuyama et al., 1985). However, there are exceptions, such as RSV and EIAV viruses (Schultz and Oroszlan, 1983), which do not have myristoylated MA proteins.

A number of structural studies have been conducted on HIV1 MA (Massiah et al., 1994; Hill et al., 1996; Tang et al., 2004; Saad et al., 2006, 2007; Alfadhli et al., 2009a). In addition to its $\mathrm{N}$-terminal myristate, which is essential for efficient membrane binding (Gottlinger et al., 1989; Bryant and Ratner, 1990; Freed et al., 1994; Spearman etal., 1994; Tang et al., 2004; Saad et al., 2006, 2007), the HIV-1 MA protein is composed of six $\alpha$ helices and three $\beta$ sheet strands (Massiah et al., 1994; Hill et al., 1996; Tang etal., 2004; Saad etal., 2006, 2007). Sedimentation equilibrium data have shown that while myristoylated HIV-1 MA exists in a monomeric-trimeric state at equilibrium, unmyristoylated MA occurs as a monomer even at high concentrations (Tang etal., 2004). NMR studies suggest that upon Gag multimerization the myristoyl group is exposed, and this fosters Gag binding to membranes (Tang et al., 2004; Saad et al., 2006, 2007).

The membrane binding face of HIV-1 MA is basic, promoting interactions with negatively charged phospholipid head groups at the inner leaflets of PMs (Massiah etal., 1994; Zhou et al., 1994; Hill et al., 1996; Tang et al., 2004; Saad et al., 2006, 2007). NMR investigations have indicated that HIV-1 MA preferentially binds to soluble PI $(4,5) \mathrm{P} 2$ mimics through contacts with the lipid head group and its $2^{\prime}$ acyl chain, and that binding promotes both

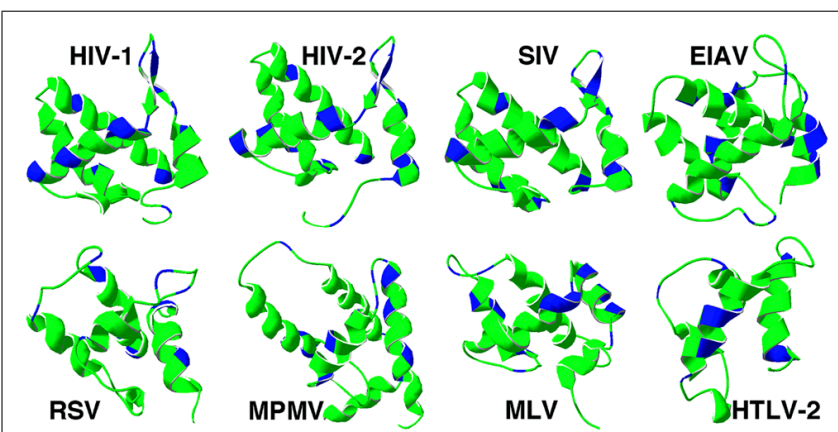

FIGURE 1 | Retrovirus matrix protein membrane binding regions. Ribbon diagrams of the membrane binding regions of four lentivirus matrix proteins (top row) and an alpharetrovirus (RSV), betaretrovirus (MPMV), gammaretrovirus (MLV), and deltaretrovirus (HTLV-2) are depicted. In each case, matrix helix one is on the right-hand side of the figure, and basic residues are indicated in blue. The PDB files for each matrix protein are as follows: HIV-1 (1UPH), HIV-2 (2K4H), SIV (1ECW), EIAV (1HEK), RSV (1A6S), MPMV (1BAX), MLV (1MN8), HTLV-2 (1JVR). exposure of the MA myristate group and protein oligomerization (Tang et al., 2004; Saad et al., 2006, 2007). Consistent with the above observations, it has been shown that HIV-1 MA and MACA proteins tend to organize as hexamers of trimers on lipid membranes containing PI(4,5)P2 (Figure 2; Alfadhli et al., 2009a), and that the binding specificity of MA is enhanced by cholesterol (Alfadhli et al., 2009a,b). These results suggest a model in which each MA trimer contributes to three separate hexamer rings, and MA proteins are positioned roughly above CA N-terminal domain (NTD) hexamers, which also are linked via CA C-terminal domain (CTD) contacts. This model implies that the shells of immature HIV-1 virions are stabilized by multiple Gag domain contacts, and has implications for how Env proteins assemble and fit into virus particles. Significantly, MA residues shown to be critical for incorporation of HIV-1 Env proteins orient toward the hexameric holes in the lattices (Yu et al., 1992; Dorfman et al., 1994; Freed and Martin, 1996; Ono et al., 1997; Murakami and Freed, 2000; Davis et al., 2006; Bhatia et al., 2007; Alfadhli et al., 2009a; Checkley et al., 2011; Tedbury et al., 2013).

\section{RETROVIRAL MA BINDING TO NUCLEIC ACIDS}

For a number of years, researchers have reported that retroviral MA proteins possess nucleic-acid-binding properties (Sen and Todaro, 1977; Leis et al., 1978, 1980; Steeg and Vogt, 1990; Katoh et al., 1991, 1993; Luban and Goff, 1991; Bukrinsky et al., 1993; Von Schwedler et al., 1994; Mansky et al., 1995; Lochrie et al., 1997;

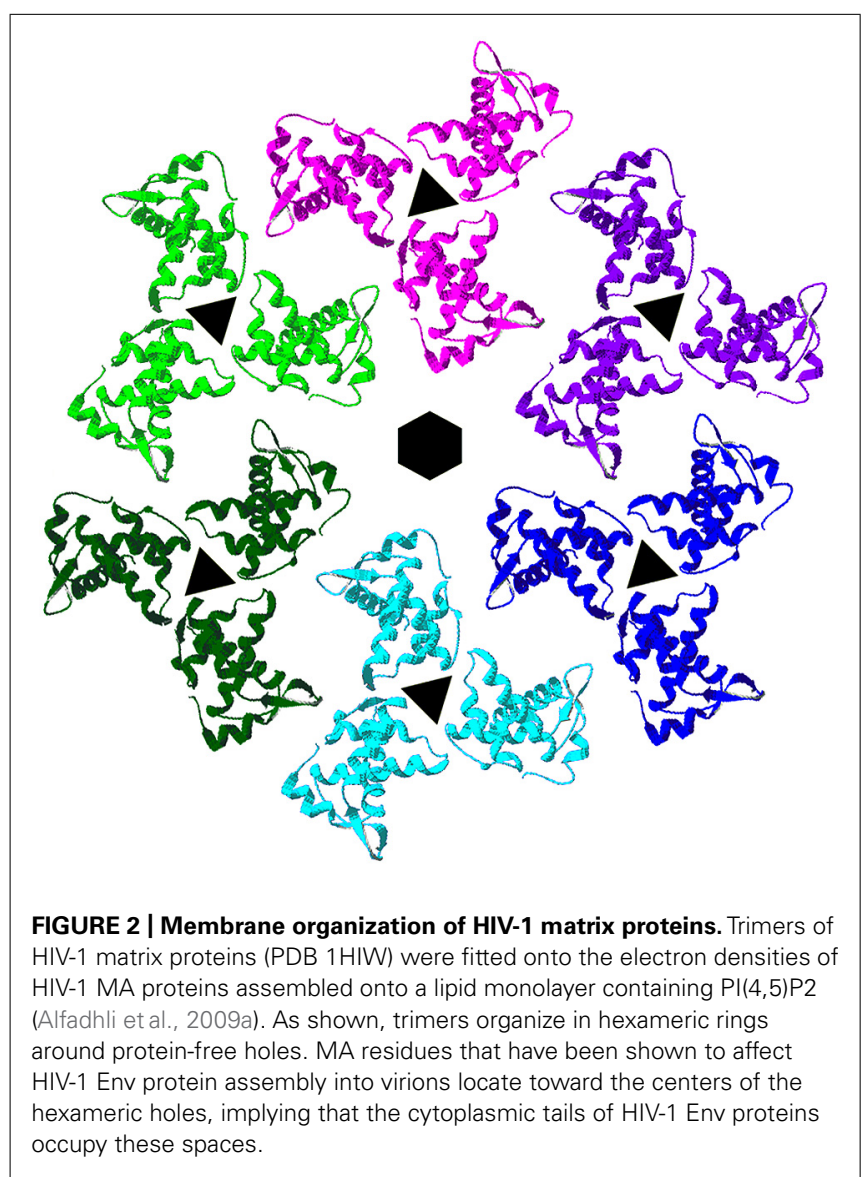


Miller et al., 1997; Swanstrom and Wills, 1997; Mansky and Wisniewski, 1998; Reil et al., 1998; Haffar et al., 2000; Garbitt et al., 2001; Purohit et al., 2001; Mansky and Gajary, 2002; Wang et al., 2003; Hearps et al., 2008; Alfadhli et al., 2009b, 2011; Cai et al., 2010; Chukkapalli et al., 2010, 2013; Chukkapalli and Ono, 2011; Monde et al., 2011). In early studies on retroviruses such as avian sarcoma and leukemia viruses (ASLV) and RSV, which is closely related to ASLV, MA was reported to be associated with vRNA in virus particles (Sen and Todaro, 1977; Leis et al., 1978, 1980), although subsequent work attributed this activity to NC (Meric et al., 1984). In any event, the binding of RSV MA to RNA is not of high specificity (Steeg and Vogt, 1990), and studies have shown that RSV MA binds to vRNA, ribosomal RNA, and DNA with similar affinities (Meric and Spahr, 1986; Parent and Gudleski, 2011).

Early studies using RNA gel mobility shift assays, and radioactive cDNA hybridization and mapping studies implicated the MA domain of BLV Gag in specific binding of vRNA (Katoh et al., 1991, 1993). Although the BLV Gag NC domain contains two zinc finger domains and basic amino acids that are important for vRNA packaging (Wang et al., 2003), the mature BLV NC proteins lack selectivity for vRNA sequences containing the encapsidation signal (Katoh etal., 1991, 1993). Surprisingly, the BLV precursor MA(p15) protein binds specifically to two distinct regions of viral RNA (Mansky and Wisniewski, 1998). This observation is discussed in more detail below.

For HIV-1, in vitro selection experiments identified RNA aptamers that showed high-affinity binding to HIV-1 MA (Lochrie et al., 1997; Purohit et al., 2001; Ramalingam et al., 2011). Lochrie et al. (1997) identified RNA ligands that bind to two different regions within Gag, either to MA or to NC. These RNAs were 50mer aptamers and had dissociation constants between 3 and $30 \mathrm{nM}$ (Lochrie et al., 1997). However, the RNA sequences identified by this screen were not related to any region on the HIV-1 vRNA (Lochrie et al., 1997). Subsequently, Purohit et al. (2001) identified high-affinity RNA ligands to HIV-1 MA that were selected by screening of random 76-mer and 31-mer RNA libraries. These investigators showed that MA binds directly to an RNA sequence that is homologous to a fragment of the pol sequence with an affinity of about $500 \mathrm{nM}$ (Purohit et al., 2001; Alfadhli et al., 2011). The region of MA that binds to this RNA was restricted to the $\mathrm{N}$-terminal basic domain, and substitution in the basic residues led to weak binding to RNA in vitro. Viral mutants that interfered with the MA-RNA interaction yielded a 4-5 day replication delay in vivo (Purohit et al., 2001). However, it is possible that mutations that affected RNA binding also affected other viral functions. In the third study (Ramalingam et al., 2011), MA-binding aptamers were found with $K_{d} \mathrm{~s}$ in the range of 100-250 nM, but expression of these aptamers in cells had only minimal effects on HIV-1 functions.

Recent studies with HIV-1 MA provide corroboration of its RNA-binding capacity. In particular, bead binding experiments have indicated that fluorescently tagged RNAs and DNAs bind well to HIV-1 MA but not to control proteins (Alfadhli et al., 2009b). Interestingly, it has been shown that RNA binding enhances the binding specificity of $\mathrm{MA}$ to $\mathrm{PI}(4,5) \mathrm{P} 2$-containing membranes. This was indicated by the fact that $\mathrm{PI}(4,5) \mathrm{P} 2$-containing liposomes successfully competed with nucleic acids for MA binding, whereas other liposomes did not (Figure 3; Alfadhli et al., 2009b). In agreement with these results, other studies have shown that the highly basic region (HBR) on the N-terminal portion of MA not only contributes to binding of $\mathrm{PI}(4,5) \mathrm{P} 2$, but also is capable of binding to RNA (Chukkapalli et al., 2008, 2010, 2013). Furthermore, RNAse treatment of in vitro translated Gag protein preparations decreased the binding specificity to membranes containing $\mathrm{PI}(4,5) \mathrm{P} 2$, suggesting that RNA influences the membrane binding specificity of MA (Chukkapalli et al., 2008, 2010, 2013, see below).

In support of these studies, it has been shown by Burniston et al. (1999) that the basic residues of the HIV-1 MA domain contribute to Gag-Gag interactions in the presence of RNA and the absence of the NC domain, indicating that the basic residues on MA play a role in RNA binding (Burniston et al., 1999). NMR studies also have confirmed interactions of HIV-1 MA with RNA and DNA, and have implicated the nucleic-binding surfaces on MA (Cai et al., 2010; Alfadhli et al., 2011). As discussed above, over a decade ago in vitro selection experiments identified a 25-mer aptamer that showed high-affinity binding to HIV-1 MA (Purohit et al., 2001). More recently, MA binding to this aptamer has been characterized. MA-RNA binding was verified via gel shift assays, fluorescence anisotropy (FA) assays, analytical ultracentrifugation, and NMR methods (Alfadhli et al., 2011).

In summary, numerous studies have shown that the MA domains from different retroviruses possess nucleic-acid-binding properties. The significance of these interactions and their plausible roles are described below.

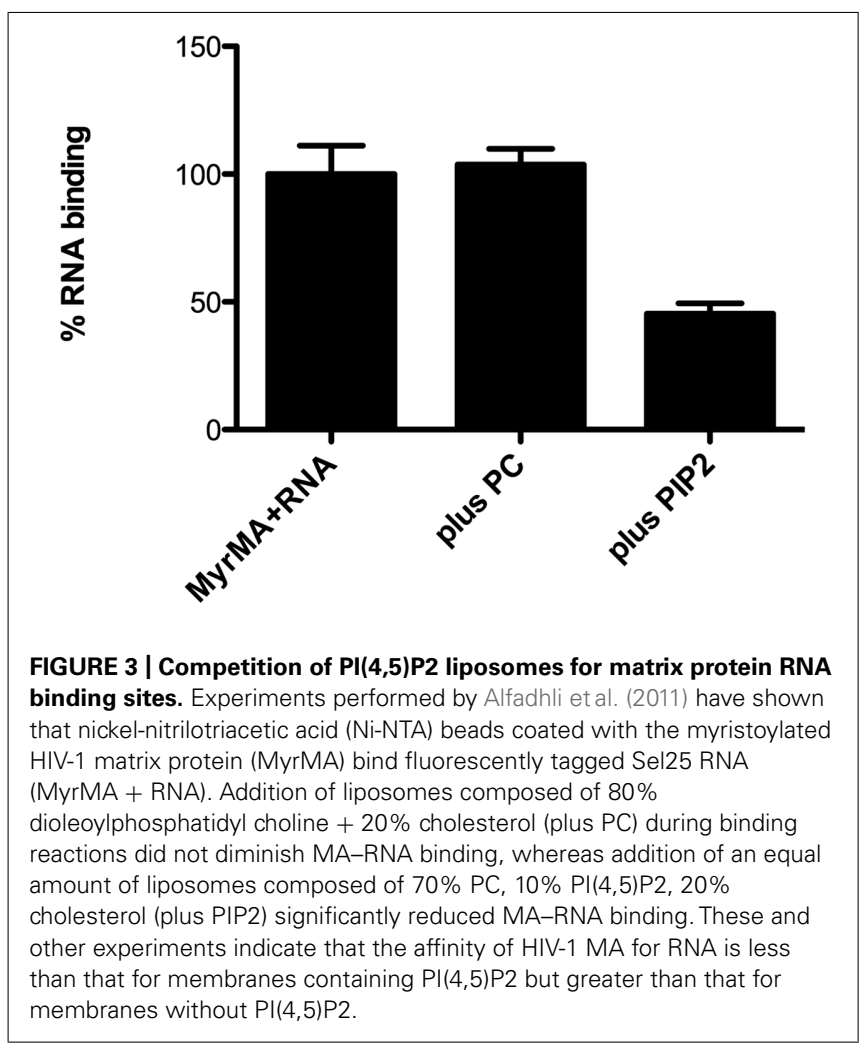




\section{THE ROLE OF MA-NUCLEIC ACID BINDING THE ROLE OF MA IN RNA ENCAPSIDATION}

The RNA encapsidation process for retroviruses involves recognition of the vRNA by the viral Gag polyprotein, and it is essential for the assembly of infectious virions. Biochemical and genetic studies have revealed that encapsidation involves the association between a stable RNA structure near the $5^{\prime}$ ends of viral genome called the encapsidation ( $\Psi$, packaging) signal and, in most cases, amino acid residues in the NC domain of the Gag protein (Mansky etal., 1995; Berkowitz et al., 1996; Swanstrom and Wills, 1997; Parent and Gudleski, 2011). It has been shown that RSV NC is essential for efficient vRNA encapsidation (Dupraz and Spahr, 1992; Aronoff et al., 1993; Lee et al., 2003; Lee and Linial, 2004; Zhou et al., 2005). However, studies have shown that other regions of RSV PrGag contribute to RNA packaging (Sakalian et al., 1994; Parent and Gudleski, 2011). In particular, mutations of the N-terminal region of RSV MA have resulted in defects in RNA dimerization and encapsidation (Sakalian et al., 1994; Garbitt-Hirst et al., 2009). The RSV Gag proteins are synthesized in the cytosol, and were believed that to be targeted directly to the plasma membrane. However, genetic and biochemical studies have indicated that RSV MA and NC domains contain nuclear localization signals (NLS) for nuclear targeting (Butterfield-Gerson et al., 2006; Garbitt-Hirst et al., 2009; Gudleski et al., 2010; Baluyot et al., 2012). Studies by Parent and co-workers have indicated that RSV MA influences vRNA encapsidation indirectly, and have proposed a working model for RSV MA role in vRNA packaging (Scheifele etal., 2002; Butterfield-Gerson et al., 2006; Garbitt-Hirst et al., 2009; Gudleski et al., 2010). According to this model, the NLS on MA binds directly to importin-11 and/or the NC NLS binds to the importin-alpha/importin-beta complex, and Gag nuclear import is directed by the importins. Once in the nucleus, Gag is released from import factors and binds to vRNA, primarily through an interaction of the NC domain with the packaging signal. RSV Gag-RNA binding may induce conformational changes in RSV Gag that expose a nuclear export signal (NES) in the Gag p10 domain (Garbitt-Hirst et al., 2009; Gudleski et al., 2010). This proposed conformational change appears to promote binding of the Gag p10 NES directly to CRM-1/RanGTP, a major exporter of RNA-binding proteins from the nucleus (Scheifele et al., 2002; Garbitt-Hirst et al., 2009; Gudleski etal., 2010). The Gag-RNA complex is then exported through the nuclear pore and travels to the plasma membrane where Gag undergoes multimerization and budding. However, it should be noted that a chimeric protein with the HIV-1 MA domain fused to the remainder of RSV Gag was able to replicate in a single round infectivity assay even though nuclear trafficking of the HIV/RSV chimeric protein was not readily detected by fluorescence microscopy (Baluyot et al., 2012).

In contrast to RSV, the BLV MA appears to play a direct role in vRNA encapsidation. While the NC domain of BLV plays a major role in genome recognition and RNA encapsidation, evidence in the literature implicates the MA protein of BLV in these events (Katoh et al., 1991, 1993; Mansky and Wisniewski, 1998). In particular, the MA domain of BLV PrGag is involved in the specific selection and packaging of vRNAs (Katoh etal., 1991,
1993; Parent and Gudleski, 2011). As one line of evidence, RNA gel mobility shift assays have shown that BLV MA binds specifically to RNAs representing the $5^{\prime}$ region of the BLV vRNA (Katoh et al., 1991, 1993). Furthermore, cDNA hybridization and mapping studies demonstrated that the BLV MA specifically binds to two different segments of the vRNA (Katoh et al., 1991, 1993). The first RNA region contains the vRNA dimerization domain, while the second RNA region is at the $5^{\prime}$ end of the gag gene, which is the location of the encapsidation signal for BLV (Mansky and Wisniewski, 1998). Interestingly, it is the BLV precursor MA (p15) protein and not the mature MA (p10) that binds specifically to the vRNA dimerization element and the encapsidation signal (Mansky and Wisniewski, 1998). Moreover, studies conducted by Katoh et al. (1991) showed that the BLV NC protein possesses only a non-specific RNA-binding activity, with little selectivity for the vRNA encapsidation signal. However, studies conducted by Mansky and co-workers provide genetic evidence that both the MA and NC domains of BLV PrGag are needed for efficient RNA packaging (Mansky et al., 1995; Mansky and Wisniewski, 1998; Mansky and Gajary, 2002; Wang et al., 2003). Mutational analysis of MA and NC showed that charged residues within both of these regions of Gag are needed for optimal genome packaging (Wang et al., 2003). In particular, mutation of residues K41 and H45 in MA, and of basic and zinc finger residues on NC resulted in BLV vRNA encapsidation defects (Wang et al., 2003). Thus, BLV provides one example in which the MA-RNA binding function is directly employed in the viral replication strategy.

\section{THE ROLE OF HIV-1 MA IN NUCLEAR IMPORT}

Historically, HIV-1 MA was the first protein implicated in directing the nuclear import of pre-integration complexes (PICs) early in infection (Bukrinsky et al., 1993; Von Schwedler et al., 1994). Reports indicated that HIV-1 MA contains an NLS that maps to the basic residues 25-33 (Bukrinsky et al., 1993; Von Schwedler et al., 1994; Depienne et al., 2000), and that mature MA enters infected cells along with vRNA and other viral proteins. Moreover, some MA molecules were found to be localized to PICs (Bukrinsky et al., 1993; Von Schwedler et al., 1994), and it thus was originally proposed that the MA NLS facilitates nuclear translocation of PICs prior to proviral integration (Bukrinsky et al., 1993; Von Schwedler et al., 1994; Miller et al., 1997; Reil et al., 1998; Haffar et al., 2000).

However, a number of reports challenged the role of HIV-1 MA in directing the nuclear import of PICs (Freed et al., 1994; Fouchier et al., 1997; Reil et al., 1998; Hearps et al., 2008). Notably, Gottlinger and co-workers showed that viruses lacking most of MA were capable of infecting non-dividing cells, suggesting that the putative MA NLS is not essential for HIV-1 replication (Reil et al., 1998; Depienne et al., 2000). Hearps et al. (2008) assessed the nuclear import properties of GFP-tagged MA, and concluded that MA is excluded from the nuclei of transfected cells. MA also failed to enter the nuclei of cells in in vitro transport assays using cells with perforated PMs but intact nuclear membranes (Hearps et al., 2008). Nevertheless, MA mutants have been shown to affect proviral DNA circularization and integration (Mannioui et al., 2005), and MA binding to DNA was demonstrated using in vitro DNA gel shift analysis (Hearps et al., 2008). Instead of a nuclear localization 
role for HIV-1 MA, these observations suggest that MA associates with PICs and augments integration. Recent NMR studies showing that MA residues $\mathrm{R} 22, \mathrm{~K} 27, \mathrm{Q} 28, \mathrm{~K} 30$, and $\mathrm{K} 32$ mediate binding to dsDNA (Cai et al., 2010) are consistent with this notion.

\section{THE ROLE OF HIV-1 MA BINDING TO RNA: REGULATION OF MEMBRANE BINDING}

Studies by Alfadhli et al. (2009b, 2011) demonstrated that MA binds to nucleic acids, and that $\mathrm{PI}(4,5) \mathrm{P} 2$-containing liposomes successfully compete with nucleic acids for MA binding, whereas other liposomes do not (Alfadhli et al., 2009b, 2011; Figure 3). Complementary studies by Ono and co-workers indicated that RNase treatment of Gag in vitro translation extracts reduced the selectivity of Gag binding for PI(4,5)P2 (Chukkapalli et al., 2010, 2013; Chukkapalli and Ono, 2011). These studies imply that MA and NC domains of HIV-1 PrGag bind to RNA in the cytoplasm of infected cells until PrGag reaches PI(4,5)P2-rich domains at the plasma membrane. By this scenario, MA-RNA binding increases the specificity of PrGag for PI(4,5)P2. This could be plausible if the MA affinity for RNA were between its affinity for PI(4,5)P2 and that for other phospholipids, so that RNA binding could protect MA from binding to inappropriate membranes (Alfadhli et al., 2009b, 2011; Chukkapalli et al., 2010, 2013; Chukkapalli and Ono, 2011). Consistent observations by Jones et al. (2011), showed that both MA and NC PrGag domains can bind nucleic acids, and that binding of MA to inositol phosphate (IP) derivatives, which resemble the PI(4,5)P2 head group, alters the association of PrGag to nucleic acids. Notably, experiments demonstrated that in vitro tRNA annealing to vRNA catalyzed by PrGag is enhanced over 10-fold by the addition of IPs to the reaction (Jones et al., 2011). In contrast, the IPs had no effect on the annealing induced by $\mathrm{NC}$ alone or CA-NC proteins. These results show that MA and NC can bind to nucleic acids, and that MA-RNA binding reduces tRNA annealing. By this model, IPs compete with vRNAs for MA binding, allowing NC to perform its encapsidation and annealing functions (Rein, 2010; Jones et al., 2011).

Another line of investigation based on biochemical and structural studies using hydrodynamic and small angle neutron scattering (SANS) methods showed that the Gag protein adopts a compact bent shaped conformation in solution. When only RNA is added, the Gag proteins assemble very small VLPs, suggesting that both MA and NC domains bind to RNA. However, in the presence of both RNA and IP membrane mimics, Gag undergoes a conformational switch to an extended rod-shaped form (Datta et al., 2007, 2011). Overall, the data above suggest that RNA provides a chaperone function in preventing HIV-1 Gag proteins from binding to membranes until they reach $\mathrm{PI}(4,5) \mathrm{P} 2$-rich plasma membranes. Such a model is depicted in Figure 4, which illustrates the binding of PrGag MA and NC domains to vRNA, followed by an MA switch to membrane binding at PM assembly sites.

To test the MA-RNA chaperone model, Ono and co-workers measured cellular RNA levels and found that they are sufficient for blocking PrGag binding to phosphatidylserine (PS; Chukkapalli et al., 2013). These results provide cell-based evidence supporting the notion that RNA regulates membrane binding, and prevents PrGag from binding promiscuously to PS-containing membranes

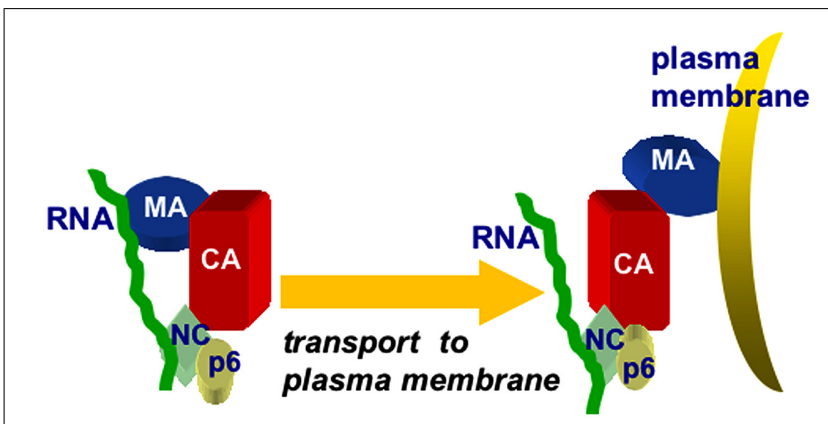

FIGURE 4 | Chaperone model for MA-RNA binding. The chaperone model for MA-RNA binding posits that both the MA and NC domains of PrGag proteins bind to RNA in the cytoplasm of infected cells, and that the MA-RNA binding protects MA from binding to inappropriate intracellular membranes, lacking PI $(4,5) \mathrm{P} 2$. Once at PI 4,5$) \mathrm{P} 2$-rich sites at the plasma membrane, MA binding switches from RNA to PI(4,5)P2, facilitating the trafficking and assembly of PrGag proteins.

(Chukkapalli et al., 2013). However, recent studies conducted by Dick et alindicate that RNA regulation of PrGag membrane binding is not universal among retroviruses (Dick et al., 2013). In contrast to HIV-1 Gag, RNAse treatment of reticulocyte lysates containing in vitro-translated RSV Gag did not alter the protein's membrane-binding characteristics. Potentially, this is because the interactions of RSV MA with RNA are weaker than those of HIV MA (Dick et al., 2013).

Given the implicated chaperone role for HIV-1 MA-nucleic acid binding (Chukkapalli et al., 2008, 2010, 2013; Alfadhli et al., 2009b, 2011), some aspects of HIV-1 MA-RNA binding have been examined further. One basic question relating to these observations concerns the nature of MA-RNA interactions. Previously, in vitro selection experiments identified a 25-mer RNA aptamer called Sel25 (GGACA GGAAU UAAUA GUAGC UGUCC) which demonstrated high-affinity binding to HIV-1 MA (Lochrie et al., 1997; Purohit et al., 2001). The central fifteen nucleotides (Sel15) also showed high-affinity binding to the protein. As a step toward characterization of MA-RNA interactions, MA binding to Sel25, Sel15, and their random sequence counterparts (Ran25, Ran15) was tracked via gel shift assays, fluorescence anisotropy (FA) assays, and analytical ultracentrifugation methods (Alfadhli et al., 2011). These investigations confirmed the specificity of MA binding to Sel15 and Sel25 RNAs. In addition, these studies identified RNA as a competitor for membrane binding, and assays indicated that $\mathrm{PI}(4,5) \mathrm{P} 2$-containing liposomes significantly reduced RNA binding to MA. In vitro competition binding experiments also showed that a soluble PI(4,5)P2 mimic (PIPC8) reduced Sel25 binding to MA, whereas a soluble PS mimic did not; while FA competition data indicated that PIPC8 reduced MA-RNA binding levels to a greater extent than did the PS mimic (Alfadhli et al., 2011). These results are consistent with the notion that RNA increases the ability of MA to distinguish between phospholipid head groups.

What MA surfaces are sensitive to RNA binding? In an attempt to address this question, NMR binding studies were performed. Using this approach, MA residues at the putative RNA binding site were identified by their chemical shift perturbations upon 
titration. In particular, significant NMR shifts were observed for residues located to the matrix protein $\beta-\mathrm{II}-\mathrm{V}$ cleft corresponding to residues Gln-28, His-33, Glu-40, Glu-42, Ile-60, Leu-68, Thr70, Glu-73, Arg-76, Ser-77, Tyr-79, and Asn-80 (Figure 5; Alfadhli et al., 2011). Some of these residues (residues 33, 73, 76, and 79) previously were shown to contribute to the $\mathrm{PI}(4,5) \mathrm{P} 2$ binding site (Figure 5; Saad et al., 2006). This observed overlap of PI(4,5)P2MA and RNA-MA binding sites reinforces a chaperone function hypothesis. These results also are in agreement with other NMR studies which implied that MA residues 28-33 and, to a lesser extent, residues 70-79 contribute to MA-DNA binding in preintegration complexes (Cai et al., 2010). It also is pertinent to note that NMR titrations indicated residues 94, 97, 103, and 104 were affected by RNA titrations (Alfadhli et al., 2011). These residues are located on MA helix VI and may involve a conformational change of MA upon RNA binding that also could affect binding specificity. While the sum of the above results support a hypothesis in which MA-RNA binding is utilized by HIV-1 to regulate virus assembly, the identity of the RNA(s) that bind to MA in vivo remains to be determined. In this regard, it is noteworthy that a nearly exact match of the Sel15 RNA sequence is located in the pol coding region of HIV-1, but while mutations of consensus

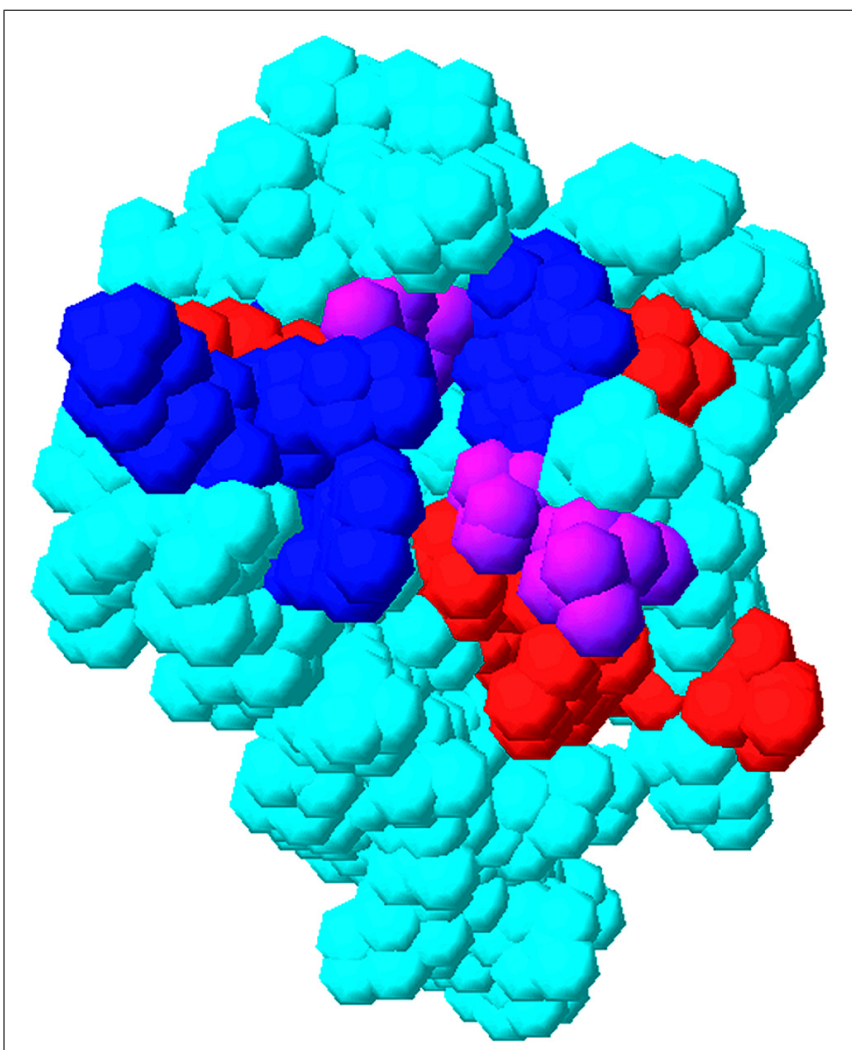

FIGURE 5 | Overlap of matrix RNA and PI(4,5)P2 binding sites. The membrane-binding surface of the HIV-1 matrix protein (PDB 1UPH) is illustrated as a space-filling model. Residues that have been implicated in $\mathrm{PI}(4,5) \mathrm{P} 2$ binding are indicated in blue, residues that have been implicated in RNA binding (Alfadhli et al., 2011) are indicated in red, and residues that have been implicated in both PI $(4,5) \mathrm{P} 2$ and RNA binding are indicated in purple. nucleotides involved in MA-Sel RNA binding reduced binding in vitro, they only modestly reduced viral infectivity in vivo (Purohit et al., 2001). Thus, it is likely that MA can bind to other sequences on viral or cellular RNAs to effect its chaperone functions.

\section{INHIBITION OF HIV-1 MA/RNA BINDING}

Despite the effectiveness of the current highly active antiretroviral therapy (HAART) in the treatment of AIDS, development of novel anti-viral strategies is dictated by the medical significance of the AIDS epidemic, side effects of current drugs, and the possible development of drug-resistant HIV strains (Larder and Kemp, 1989; Richman et al., 1991; Moreno et al., 2010). The process of virus assembly, controlled by the HIV-1 Gag proteins, represents an attractive target for such therapies. Findings on the interplay between MA and RNA lay a foundation for determining how HIV1 MA matrix binds RNA, and the role of MA-RNA interactions in HIV replication. Furthermore, these findings pave the way for efforts to use the MA-RNA interaction as a potential target for a new class of HIV assembly inhibitors. These interactions can be monitored with in vitro techniques, making them suitable for screening purposes. Consequently, assays that facilitate the identification of potential inhibitors of MA-RNA interactions have been developed. The reasoning here is that molecules that interfere with the binding of RNAs to MA may impair either an essential MARNA binding function, the overlapping MA-PI(4,5)P2 binding function, or both. Based on this, we have designed novel high throughput screens (HTS) in which small-molecule competitors to MA-RNA binding may be identified. The basic assay involves binding of C-terminally His-tagged MyrMA to 96-well nickelNTA plates, incubation of the plates with biotin-Sel15 RNA in the presence or absence of potential competitors, and colorimetric determination of bound biotin-Sel15 (Alfadhli et al., 2013). Using the MA-RNA binding assay, a library of 14,000 compounds was screened for inhibition of MyrMA-Sel15 RNA binding, looking for candidates that significantly reduced Sel15 RNA binding to MyrMA. The robustness of the assay was indicated by the consistently large difference between samples containing no inhibitor versus those using untagged Sel15 RNA as an inhibitor control, and a favorable $\mathrm{Z}$ screening window coefficient (Zhang et al., 1999) of 0.69 for the screen. Using this assay, a small group of compounds that compete with RNA for MA binding was identified. Interestingly, three of the four best inhibitor candidates were thiadiazolanes. These potential inhibitors were characterized with respect to MA binding by NMR, FA, and electrophoretic mobility shift assays (EMSA). Importantly, results showed that MA-thiadiazolanes binding sites do overlap the MA-RNA binding site, validating the concept of such a screening effort. The thiadiazolanes also were shown to inhibit HIV-1 replication in cell culture, but unfortunately also demonstrated cytotoxicity in the 10-20 mM range (Alfadhli et al., 2013). Despite this, such efforts should open the door to the development of new classes of HIV antivirals that target MA and its nucleic-acid-binding pocket.

\section{ACKNOWLEDGMENTS}

The authors gratefully acknowledge support from NIH grants R01 GM060170 and R01 GM101983. 


\section{REFERENCES}

Akari, H., Fukumori, T., and Adachi, A. (2000). Cell-dependent requirement of human immunodeficiency virus type $1 \mathrm{gp} 41$ cytoplasmic tail for Env incorporation into virions. J. Virol. 74, 4891-4893. doi: 10.1128/JVI.74.10.48914893.2000

Alfadhli, A., Barklis, R. L., and Barklis, E. (2009a). HIV-1 matrix organizes as a hexamer of trimers on membranes containing phosphatidylinositol- $(4,5)$ bisphosphate. Virology 387, 466-472. doi: 10.1016/j.virol.2009.02.048

Alfadhli, A., Still, A., and Barklis, E. (2009b). Analysis of human immunodeficiency virus type 1 matrix binding to membranes and nucleic acids. J. Virol. 83, 1219612203. doi: 10.1128/JVI.01197-09

Alfadhli, A., McNett, H., Eccles, J., Tsagli, S., Noviello, C., Sloan, R., et al. (2013). Analysis of small molecule ligands targeting the HIV-1 matrix protein-RNA binding site. J. Biol. Chem. 288, 666-676. doi: 10.1074/jbc.M112.399865

Alfadhli, A., McNett, H., Tsagli, S., Bachinger, H. P., Peyton, D. H., and Barklis, E. (2011). HIV-1 matrix protein binding to RNA. J. Mol. Biol. 410, 653-666. doi: 10.1016/j.jmb.2011.04.063

Aronoff, R., Hajjar, A. M., and Linial, M. L. (1993). Avian retroviral RNA encapsidation: reexamination of functional $5^{\prime}$ RNA sequences and the role of nucleocapsid Cys-His motifs. J. Virol. 67, 178-188.

Arthur, L. O., Bess, J. W., Sowde, R. C., Benveniste, R. E., Mann, D. L., Chermann, J. C., et al. (1992). Cellular proteins bound to immunodeficiency viruses: implications for pathogenesis and vaccines. Science 258, 1935-1938. doi: 10.1126/science.1470916

Baluyot, M. F., Grosse, S. A., Lyddon, T. D., Janaka, S. K., and Johnson, M. C. (2012). CRM1-dependent trafficking of retroviral Gag proteins revisited. J. Virol. 86, 469-4700. doi: 10.1128/JVI.07199-11

Berkowitz, R., Fisher, J., and Goff, S. P. (1996). RNA packaging. Curr. Top. Microbiol. Immunol. 214, 177-218. doi: 10.1007/978-3-642-80145-7_6

Bhatia, A. K., Campbell, N., Panganiban, A., and Ratner, L. (2007). Characterization of replication defects induced by mutations in the basic domain and C-terminus of HIV-1 matrix. Virology 369, 47-54. doi: 10.1016/j.virol.2007.06.046

Bouamr, F., Scarlata, S., and Carter, C. (2003). Role of myristylation in HIV-1 Gag assembly. Biochemistry 42, 6408-6417. doi: 10.1021/bi020692z

Bryant, M., and Ratner, L. (1990). Myristoylation-dependent replication and assembly of human immunodeficiency virus 1. Proc. Natl. Acad. Sci. U.S.A. 87, 523-527. doi: 10.1073/pnas.87.2.523

Bukrinsky, M. I., Haggerty, S., Dempsey, M. P., Sharova, N., Adzhubel, A., Spitz, L., et al. (1993). A nuclear localization signal within HIV-1 matrix protein that governs infection of non-dividing cells. Nature 365, 666-669. doi: $10.1038 / 365666 \mathrm{a} 0$

Burniston, M. T., Cimarelli, A., Colgan, J., Curtis, S. P., and Luban, J. (1999). Human immunodeficiency virus type $1 \mathrm{Gag}$ polyprotein multi-merization requires the nucleocapsid domain and RNA and is promoted by the capsid-dimer interface and the basic region of matrix protein. J. Virol. 73, 8527-8540.

Butterfield-Gerson, K. L., Scheifele, L. Z., Ryan, E. P., Hopper, A. K., and Parent, L. J. (2006). Importin beta family members mediate alpharetrovirus Gag nuclear entry via interactions with MA and NC. J. Virol. 80, 1798-1806. doi: 10.1128/JVI.80.4.1798-1806.2006

Cai, M., Huang, Y., Craigie, R., and Clore, G. M. (2010). Structural basis of the association of HIV-1 matrix protein with DNA. PLOS ONE 5:e15675. doi: 10.1371/journal.pone.0015675

Callahan, E. M., and Wills, J. W. (2000). Repositioning basic residues in the M domain of the Rous sarcoma virus gag protein. J. Virol. 74, 11222-11229. doi: 10.1128/JVI.74.23.11222-11229.2000

Campbell, S., Fisher, R. J., Towler, E. M., Fox, S., Issaq, H. J., Wolfe, T., et al. (2001). Modulation of HIV-like particle assembly in vitro by inositol phosphates. Proc. Natl. Acad. Sci. U.S.A. 98, 10875-10879. doi: 10.1073/pnas.191224698

Campbell, S., and Rein, A. (1999). In vitro assembly properties of human immunodeficiency virus type 1 Gag protein lacking the p6 domain. J. Virol. 73 , 2270-2279.

Campbell, S., and Vogt, V. M. (1995). Self-assembly in vitro of purified CA-NC proteins from Rous sarcoma virus and human immunodeficiency virus type 1 . J. Virol. 69, 6487-6497.

Chan, J., Dick, R. A., and Vogt, V. M. (2011). Rous sarcoma virus Gag has no specific requirement for phosphatidylinositol- $(4,5)$-bisphosphate for plasma membrane association in vivo or for liposome interaction in vitro. J. Virol. 85, 10851-10860. doi: 10.1128/JVI.00760-11
Chan, R., Uchil, P. D., Jin, J., Shui, G., Ott, D. E., Mothes, W., et al. (2008). Retroviruses human immunodeficiency virus and murine leukemia virus are enriched in phosphoinositides. J. Virol. 82, 11228-11238. doi: 10.1128/JVI.00981-08

Checkley, M. A., Luttge, B. G., and Freed, E. O. (2011). HIV-1 envelope glycoprotein biosynthesis, trafficking, and incorporation. J. Mol. Biol. 410, 582-608. doi: 10.1016/j.jmb.2011.04.042

Chen, K., Bachtiar, I., Piszczek, G., Bouamr, F., Carter, C., and Tjandra, N. (2008). Solution NMR characterization of oligomerization and dynamics of equine infectious anemia virus matrix protein and its interaction with PIP2. Biochemistry 47, 1928-1937. doi: 10.1021/bi701984h

Choi, G., Park, S., Choi, B., Hong, S., Lee, J., Hunter, E., et al. (1999). Identification of a cytoplasmic targeting/retention signal in a retroviral Gag polyprotein. J. Virol. 73, 5431-5437.

Christensen, A. M., Massiah, M. A., Turner, B. G., Sundquist, W. I., and Summers, M. F. (1996). Three-dimensional structure of the HTLV-II matrix protein and comparative analysis of matrix proteins from the different classes of pathogenic human retroviruses. J. Mol. Biol. 264, 1117-1131. doi: 10.1006/jmbi.1996.0700

Chukkapalli, V., Hogue, I. B., Boyko, V., Hu, W. S., and Ono, A. (2008). Interaction between HIV-1 Gag matrix domain and phosphatidylinositol-(4,5)-bisphosphate is essential for efficient Gag-membrane binding. J. Virol. 82, 2405-2417. doi: 10.1128/JVI.01614-07

Chukkapalli, V., Inlora, J., Todd, G. C., and Ono, A. (2013). Evidence in support of RNA-mediated inhibition of phosphatidylserine-dependent HIV-1 Gag membrane binding in cells. J. Virol. 87, 7155-7159. doi: 10.1128/JVI.00075-13

Chukkapalli, V., Oh, S. J., and Ono, A. (2010). Opposing mechanisms involving RNA and lipids regulate HIV-1 Gag membrane binding through the highly basic region of the matrix domain. Proc. Natl. Acad. Sci. U.S.A. 107, 1600-1605. doi: 10.1073/pnas.0908661107

Chukkapalli, V., and Ono, A. (2011). Molecular determinants that regulate plasma membrane association of HIV-1 Gag. J. Mol. Biol. 410, 512-524. doi: 10.1016/j.jmb.2011.04.015

Coffin, J. M., Hughes, S. H., and Varmus, H. E. (1997). "The interactions of retroviruses and their hosts," in Retroviruses, eds J. Coffin, S. Hughes, and H. Varmus (Cold Spring Harbor, NY: Cold Spring Harbor Laboratory Press).

Conte, M. R., Klikova, M., Hunter, E., Ruml, T., and Matthews, S. (1997). The three-dimensional solution structure of the matrix pro-tein from the type D retrovirus, the Mason-Pfizer monkey virus, and implications for the morphology of retroviral assembly. EMBO J. 16, 5819-5827. doi: 10.1093/emboj/16.19.5819

Cosson, P. (1996). Direct interaction between the envelope and matrix proteins of HIV-1. EMBO J. 15, 5783-5788.

Cronin, J., Zhang, X. Y., and Reiser, J. (2005). Altering the tropism of lentiviral vectors through pseudotyping. Curr. Gene Ther. 5, 387-398. doi: 10.2174/1566523054546224

Dalton, A. K., Ako-Adjei, D., Murray, P. S., Murray, D., and Vogt, V. M. (2007). Electrostatic interactions drive membrane association of the human immunodeficiency virus type 1 Gag MA domain. J. Virol. 81, 6434-6445. doi: 10.1128/JVI.02757-06

Dalton, A. K., Murray, P. S., Murray, D., and Vogt, V. M. (2005). Biochemical characterization of Rous sarcoma virus MA protein interaction with membranes. J. Virol. 79, 6227-6238. doi: 10.1128/JVI.79.10.6227-6238.2005

Datta, S. A., Curtis, J. E., Ratcliff, W., Clark, P. K., Crist, R. M., Lebowitz, J., et al. (2007). Conformation of the HIV-1 Gag protein in solution. J. Mol. Biol. 365, 812-824. doi: 10.1016/j.jmb.2006.10.073

Datta, S. A., Heinrich, F., Raghunandan, S., Krueger, S., Curtis, J. E., Rein, A., et al. (2011). HIV-1 Gag extension: conformational changes require simultaneous interaction with membrane and nucleic acid. J. Mol. Biol. 406, 205-214. doi: 10.1016/j.jmb.2010.11.051

Davis, M. R., Jiang, J., Zhou, J., Freed, E. O., and Aiken, C. (2006). A mutation in the human immunodeficiency virus type 1 Gag protein destabilizes the interaction of the envelope protein subunits gp120 and gp41. J. Virol. 80, 2405-2417. doi: 10.1128/JVI.80.5.2405-2417.2006

Depienne, C., Roques, P., Creminon, C., Fritsch, L., Casseron, R., Dormont, D., et al. (2000). Cellular distribution and karyophilic properties of matrix, integrase, and Vpr proteins from the human and simian immunodeficiency viruses. Exp. Cell Res. 260, 387-395. doi: 10.1006/excr.2000.5016

Dick, R. A., Kamynina, E., and Vogt, V. M. (2013). Effect of multimerization on membrane association of Rous sarcoma virus and HIV-1 matrix domain proteins. J. Virol. 87, 13598-13608. doi: 10.1128/JVI.01659-13 
Dorfman, T., Bukovsky, A., Ohagen, A., Hoglund, S., and Gottlinger, H. G. (1994). Functional domains of the capsid protein of human immunodeficiency virus type 1. J. Virol. 68, 8180-8187.

Dupraz, P., and Spahr, P. (1992). Specificity of Rous sarcoma virus nucleocapsid protein in genomic RNA packaging. J. Virol. 66, 4662-4670.

Ehrlich, L. S., Fong, S., Scarlata, S., Zybarth, G., and Carter, C. (1996). Partitioning of HIV-1 Gag and Gag-related proteins to membranes. Biochemistry 35, 3933-3943. doi: $10.1021 /$ bi952337x

Erdie, C. R., and Wills, J. W. (1990). Myristoylation of Rous sarcoma virus Gag protein does not prevent replication in avian cells. J. Virol. 64, 5204-5208.

Fouchier, R. A., Meyer, B. E., Simon, J. H., Fischer, U., and Malim, M. H. (1997) HIV-1 infection of non-dividing cells: evidence that the amino-terminal basic region of the viral matrix protein is important for Gag processing but not for post-entry nuclear import. EMBO J. 16, 4531-4539. doi: 10.1093/emboj/16. 15.4531

Freed, E. O. (1998). HIV-1 gag proteins: diverse functions in the virus life cycle. Virology 251, 1-15. doi: 10.1006/viro.1998.9398

Freed, E. O., and Martin, M. A. (1995). The role of human immunodeficiency virus type 1 envelope glycoproteins in virus infection. J. Biol. Chem. 270, 23883-23886. doi: $10.1074 /$ jbc. 270.41 .23883

Freed, E. O., and Martin, M. A. (1996). Domains of the human immunodeficiency virus type 1 matrix and gp 41 cytoplasmic tail required for envelope incorporation into virions. J. Virol. 70, 341-351.

Freed, E. O., Orenstein, J. M., Buckler-White, A. J., and Martin, M. A. (1994). Single amino acid changes in the human immunodeficiency virus type 1 matrix protein block virus particle production. J. Virol. 68, 5311-5320.

Garbitt, R. A., Albert, J. A., Kessler, M. D., and Parent, L. J. (2001). Transacting inhibition of genomic RNA dimerization by Rous sarcoma virus matrix mutants. J. Virol. 75, 260-268. doi: 10.1128/JVI.75.1.260268.2001

Garbitt-Hirst, R., Kenney, S. P., and Parent, L. J. (2009). Genetic evidence for a connection between Rous sarcoma virus gag nuclear trafficking and genomic RNA packaging. J. Virol. 83, 6790-6797. doi: 10.1128/JVI.75.1.260-268.2001

Goff, S. P. (2001). "Retroviridae: the retroviruses and their replication," in Fundamental Virology, eds D. M. Knipe and P. M. Howley (Philadelphia, PA: Lippincott Williams and Wilkins), 843-912. doi: 10.1128/JVI.00101-09

Gottlinger, H. G., Sodroski, J. G., and Haseltine, W. A. (1989). Role of capsid precursor processing and myristoylation in morphogenesis and infectivity of human immunodeficiency virus type 1. Proc. Natl. Acad. Sci. U.S.A. 86, 5781-5785. doi: 10.1073/pnas.86.15.5781

Gross, I., Hohenberg, H., Wilk, T., Wiegers, K., Grättinger, M., Müller, B., et al. (2000). A conformational switch controlling HIV-1 morphogenesis. EMBO J. 19, 103-113. doi: 10.1093/emboj/19.1.103

Gudleski, N., Flanagan, J. M., Ryan, E. P., Bewley, M. C., and Parent, L. J. (2010). Directionality of nucleocytoplasmic transport of the retroviral gag protein depends on sequential binding of karyopherins and viral RNA. Proc. Natl. Acad. Sci. U.S.A. 107, 9358-9363. doi: 10.1073/pnas.1000304107

Haffar, O. K., Popov, S., Dubrovsky, L., Agostini, I., Tang, H., Pushkarsky, T., et al. (2000). Two nuclear localization signals in the HIV-1 matrix protein regulate nuclear import of the HIV-1 pre-integration complex. J. Mol. Biol. 299, 359-368. doi: 10.1006/jmbi.2000.3768

Hamard-Peron, E., and Muriaux, D. (2011). Retroviral matrix and lipids, the intimate interactions. Retrovirology 8, 15. doi: 10.1186/1742-4690-8-15

Hamard-Peron, E., Juilliard, F., Saad, J. S., Roy, C., Roingeard, P., Summers, M. F., et al. (2010). Targeting of MuLV Gag to the plasma membrane is mediated by $\mathrm{PI}(4,5) \mathrm{P} 2 / \mathrm{PS}$ and a polybasic region in the matrix. J. Virol. 84, 503-515. doi: 10.1128/JVI.01134-09

Hatanaka, H., Iourin, O., Rao, Z., Fry, E., Kingsman, A., and Stuart, D. I. (2002). Structure of equine infectious anemia virus matrix protein. J. Virol. 76, 18761883. doi: 10.1128/JVI.76.4.1876-1883.2002

Hearps, A. C., Wagstaff, K. M., Piller, S. C., and Jans, D. A. (2008). The N-terminal basic domain of the HIV-1 matrix protein does not contain a conventional nuclear localization sequence but is required for DNA binding and protein self-association. Biochemistry 47, 2199-2210. doi: 10.1021/bi701360j

Henderson, L. E., Krutzsch, H. C., and Oroszlan, S. (1983). Myristyl aminoterminal acylation of murine retrovirus proteins: an unusual post-translational proteins modification. Proc. Natl. Acad. Sci. U.S.A. 80, 339-343. doi: 10.1073/pnas.80.2.339
Hill, C. P., Worthylake, D., Bancroft, D. P., Christensen, A. M., and Sundquist, W. I. (1996). Crystal structures of the trimeric human immunodeficiency virus type 1 matrix protein: implications for membrane association and assembly. Proc. Natl. Acad. Sci. U.S.A. 93, 3099-3104. doi: 10.1073/pnas.93. 7.3099

Inlora, J., Chukkapalli, V., Derse, D., and Ono, A. (2011). Gag localization and viruslike particle release mediated by the matrix domain of human T-lymphotropic virus type $1 \mathrm{Gag}$ are less dependent on phosphatidylinositol-(4,5)-bisphosphate than those mediated by the matrix domain of HIV-1 Gag. J. Virol. 85, 3802-3810. doi: 10.1128/JVI.02383-10

Jiang, J., and Aiken, C. (2007). Maturation-dependent human immunodeficiency virus type 1 particle fusion requires a carboxyl-terminal region of the gp41 cytoplasmic tail. J. Virol. 81, 9999-10008. doi: 10.1128/JVI.00592-07

Jones, C. P., Datta, S. A., Rein, A., Rouzina, I., and Musier-Forsyth, K. (2011). Matrix domain modulates HIV-1 Gag's nucleic acid chaperone activity via inositol phosphate binding. J. Virol. 85, 1594-1603. doi: 10.1128/JVI. 01809-10

Jorgenson, R. L., Vogt, V. M., and Johnson, M. C. (2009). Foreign glycoproteins can be actively recruited to virus assembly sites during pseudotyping. J. Virol. 83, 4060-4067. doi: 10.1128/JVI.02425-08

Jouvenet, N., Bieniasz, P. D., and Simon, S. M. (2008). Imaging the biogenesis of individual HIV-1 virions in live cells. Nature 454, 236-240. doi: 10.1038 /nature 06998

Jouvenet, N., Neil, S. J., Bess, C., Johnson, M. C., Virgen, C. A., Simon, S. M., et al. (2006). Plasma membrane is the site of productive HIV-1 particle assembly. PLoS Biol. 4:e435. doi: 10.1371/journal.pbio.0040435

Katoh, I.,Kyushiki, H., Sakamoto, y.,Ikawa, y., and Yoshinaka, Y. (1991). Bovine leukemia virus matrix-associated protein $\mathrm{MA}(\mathrm{p} 15)$ : further processing and formation of a specific complex with the dimer of the $5^{\prime}$ terminal genomic RNA fragment. J. Virol. 65, 6845-6855.

Katoh, I., Yasunaga, T., and Yoshinaka, Y. (1993). Bovine leukemia virus RNA ?sequences involved in dimerization and specific gag protein binding: close relation to the packaging sites of avian, murine, and human retroviruses. J. Virol. 67, 1830-1839

Landau, N. R., Page, K. A., and Littman, D. R. (1991). Pseudotyping with human T-cell leukemia virus type I broadens the human immunodeficiency virus host range. J. Virol. 65, 162-169.

Larder, B. A., and Kemp, S. D. (1989). Multiple mutations in HIV-1 reverse transcriptase confer high-level resistance to zidovudine (AZT). Science 246, 1155-1158. doi: 10.1126/science. 2479983

Lee, E. G., Alidina, A., May, C., and Linial, M. L. (2003). Importance of basic residues in binding of Rous sarcoma virus nucleocapsid to the RNA packaging signal. J. Virol. 77, 2010-2020. doi: 10.1128/JVI.77.3.20102020.2003

Lee, E. G., and Linial, M. L. (2004). Basic residues of the retroviral nucleocapsid play different roles in Gag-Gag and Gag-\{Psi\} RNA interactions. J. Virol. 78, 8486-8495. doi: 10.1128/JVI.78.16.8486-8495.2004

Leis, J. P., McGinnis, J., and Green, R. W. (1978). Rous sarcoma virus p19 binds to specific double-stranded regions of viral RNA: effect of p19 on cleavage of viral RNA by RNase III. Virology 84, 87-98. doi: 10.1016/0042-6822(78) 90220-9

Leis, J. P., Scheible, P., and Smith, R. E. (1980). Correlation of RNA binding affinity of avian oncornavirus $\mathrm{p} 19$ proteins with the extent of processing of virus genome RNA in cells. J. Virol. 35, 722-731.

Lewis, B. C., Chinnasamy, N., Morgan, R. A., and Varmus, H. E. (2001). Development of an avian leukosis-sarcoma virus subgroup A pseudotyped lentiviral vector. J. Virol. 75, 9339-9344. doi: 10.1128/JVI.75.19.9339-9344. 2001

Liu, S. L., Halbert, C. L., and Miller, A. D. (2004). Jaagsiekte sheep retrovirus envelope efficiently pseudotypes human immunodeficiency virus type 1-based lentiviral vectors. J. Virol. 78, 2642-2647. doi: 10.1128/JVI.78.5.26422647.2003

Lochrie, M. A., Waugh, S., Pratt, D. G. J., Clever, J., Parslow, T. G., and Polisky, B. (1997). In vitro selection of RNAs that bind to the human immunodeficiency virus type-1 gag polyprotein. Nucleic Acids Res. 25, 2902-2910. doi: $10.1093 /$ nar/25.14.2902

Luban, J., and Goff, S. P. (1991). Binding of human immunodeficiency virus type 1 (HIV-1) RNA to recombinant HIV-1 gag polyprotein. J. Virol. 65, 3203-3212. 
Lusso, P., di Marzo, Veronese, F., Ensoli, B., Franchini, G., Jemma, C., Derocco, S. E., et al. (1990). Expanded HIV-1 cellular tropism by phenotypic mixing with murine endogenous retroviruses. Science 247, 848-852. doi: 10.1126/science.2305256

Mannioui, A., Nelson, E., Schiffer, C., Felix, N., Le Rouzic, E., Benichou, S., et al. (2005). Human immunodeficiency virus type 1 KK26-27 matrix mutants display impaired infectivity, circularization and integration but not nuclear import. Virology 339, 21-30. doi: 10.1016/j.virol.2005.05.023

Manrique, J. M., Affranchino, J. L., and Gonzalez, S. A. (2008). In vitro binding of simian immunodeficiency virus matrix protein to the cytoplasmic domain of the envelope glycoprotein. Virology 374, 273-279. doi: 10.1016/j.virol.2008. 01.015

Mansky, L. M., and Gajary, L. C. (2002). The primary nucleotide sequence of the bovine leukemia virus RNA packaging signal can influence efficient RNA packaging and virus replication. Virology 301, 272-280. doi: 10.1006/viro.2002.1578

Mansky, L. M., Krueger, A. E., and Temin, H. M. (1995). The bovine leukemia virus encapsidation signal is discontinuous and extends into the $5^{\prime}$ end of the gag gene. J. Virol. 69, 3282-3289.

Mansky, L. M., and Wisniewski, R. M. (1998). The bovine leukemia virus encapsidation signal is composed of RNA secondary structures. J. Virol. 72, 3196-3204.

Massiah, M. A., Starich, M. R., Paschall, C., Summers, M. F., Christensen, A. M., and Sunquist, W. I. (1994). Three-dimensional structure of the human immunodeficiency virus type 1 matrix protein. J. Mol. Biol. 244, 198-223. doi: 10.1006/jmbi.1994.1719

Matthews, S., Mikhailov, M., Burny, A., and Roy, P. (1996). The solution structure of the bovine leukaemia virus matrix protein and similarity with lentiviral matrix proteins. EMBO J. 15, 3267-3274.

McDonnell, J. M., Fushman, D., Cahill, S. M., Zhou, W., Wolven, A., Wilson, C. B., etal. (1998). Solution structure and dynamics of the bioactive retroviral M domain from Rous sarcoma virus. J. Mol. Biol. 279, 921-928. doi: 10.1006/jmbi.1998.1788

Meric, C., Darlix, J. L., Spahr, P. F. (1984). It is Rous sarcoma virus protein P12 and not P19 that binds tightly to Rous sarcoma virus RNA. J. Mol. Biol. 173, 531-538. doi: 10.1016/0022-2836(84)90396-6

Meric, C., and Spahr, P. (1986). Rous sarcoma virus nucleic-acid binding protein p12 is necessary for viral $70 \mathrm{~S}$ dimer formation and packaging. J. Virol. 60, 450-459.

Mervis, R. J., Ahmad, N., Lillehoj, E. P., Raum, M. G., Salazar, F. H., Chan, H. W., et al. (1988). The gag gene products of human immunodeficiency virus type 1: alignment within the gag open reading frame, identification of posttranslational modifications, and evidence for alternative gag precursors. J. Virol. 62, 3993-4002.

Miller, M. D., Farnet, C. M., and Bushman, F. D. (1997). Human immunodeficiency virus type 1 preintegration complexes: studies of organization and composition. J. Virol. 71, 5382-5390.

Monde, K., Chukkapalli, V., and Ono, A. (2011). Assembly and replication of HIV-1 in T cells with low levels of phosphatidylinositol-(4,5)-bisphosphate. J. Virol. 85 , 3584-3595. doi: 10.1128/JVI.02266-10

Moreno, S., Lopez Aldeguer, J., Arribas, J. R., Domingo, P., Iribarren, J. A., Ribera, E., etal. (2010). The future of antiretroviral therapy: challenges and needs. J. Antimicrob. Chemother. 65, 827-835. doi: 10.1093/jac/ dkq061

Morikawa, Y., Hockley, D. J., Nermut, M. V., and Jones, I. M. (2000). Roles of matrix, $\mathrm{p} 2$, and $\mathrm{N}$-terminal myristoylation in human immunodeficiency virus typel Gag assembly. J. Virol. 74, 16-23. doi: 10.1128/JVI.74.1.16-23.2000

Murakami, T., Ablan, S. D., Freed, E. O., and Tanaka, Y. (2004). Regulation of human immunodeficiency virus type 1 Env-mediated membrane fusion by viral protease activity. J. Virol. 78, 1026-1031. doi: 10.1128/JVI.78.2.1026-1031.2004

Murakami, T., and Freed, E. O. (2000). The long cytoplasmic tail of gp41 is required in a cell type-dependent manner for HIV-1 envelope glycoprotein incorporation into virions. Proc. Natl. Acad. Sci. U.S.A. 97, 343-348. doi: 10.1073/pnas.97. 1.343

Muriaux, D., Costes, S., Nagashima, K., Mirro, J., Cho, E., Lockett, S., et al. (2004). Role of murine leukemia virus nucleocapsid protein in virus assembly. J. Virol. 78, 12378-12385. doi: 10.1128/JVI.78.22.12378-12385.2004

Muriaux, D., Mirro, J., Harvin, D., and Rein, A. (2001). RNA is a structural element in retrovirus particles. Proc. Natl. Acad. Sci. U.S.A. 98, 5246-5251. doi 10.1073/pnas.091000398

Murray, P. S., Li, Z., Wang, J., Tang, C. L., Honig, B., and Murray, D. (2005). Retroviral matrix domains share electrostatic homology: models for membrane binding function throughout the viral life cycle. Structure 13, 1521-1531. doi: 10.1016/j.str.2005.07.010

Nadaraia-Hoke, S., Bann, D. V., Lochmann, T. L., Gudleski-O' Regan, N., and Parent, L. J. (2013). Alterations in the MA and NC domains modulate phosphoinositidedependent plasma membrane localization of the Rous sarcoma virus Gag protein. J. Virol. 87, 3609-3615. doi: 10.1128/JVI.03059-12

Ono, A., Ablan, S. D., Lockett, S. J., Nagashima, K., and Freed, E. O. (2004). Phosphatidylinositol $(4,5)$ bisphosphate regulates HIV-1 Gag targeting to the plasma membrane. Proc. Natl. Acad. Sci. U.S.A. 101, 14889-14894. doi: 10.1073/pnas.0405596101

Ono, A., and Freed, E. O. (1999). Binding of human immunodeficiency virus type 1 Gag to membrane: role of the matrix amino terminus. J. Virol. 73, 4136-4144.

Ono, A., and Freed, E. O. (2001). Plasma membrane rafts play a critical role in HIV-1 assembly and release. Proc. Natl. Acad. Sci. U.S.A. 98, 13925-13930. doi: $10.1073 /$ pnas. 241320298

Ono, A., Huang, M., and Freed, E. O. (1997). Characterization of human immunodeficiency virus type 1 matrix revertants: effects on virus assembly, Gag processing, and Env incorporation into virions. J. Virol. 71, 4409-4418.

Ono, A., Orenstein, J. M., and Freed, E. O. (2000). Role of the Gag matrix domain in targeting human immunodeficiency virus type 1 assembly. J. Virol. 74, 2855-2866. doi: 10.1128/JVI.74.6.2855-2866.2000

Ootsuyama, Y., Shimotohno, K., Miwa, M., Oroszlan, S., and Sugimura, T. (1985) Myristylation of gag protein in human. T-cell leukemia virus type-I and type-II. Jpn. J. Cancer Res. 76, 1132-1135.

Ott, D. E. (2008). Cellular proteins detected in HIV-1. Rev. Med. Virol. 18, 159-175. doi: $10.1002 /$ rmv.570

Ott, D. E., Coren, L. V., and Gagliardi, T. D. (2005). Redundant roles for nucleocapsid and matrix RNA-binding sequences in human immunodeficiency virus type 1 assembly. J. Virol. 79, 13839-13847. doi: 10.1128/JVI.79.22.13839-138 47.2005

Ott, D. E., Coren, L. V., and Shatzer, T. (2009). The nucleocapsid region of human immunodeficiency virus type $1 \mathrm{Gag}$ assists in the coordination of assembly and Gag processing: role for RNA-Gag binding in the early stages of assembly. J. Virol. 83, 7718-7727. doi: 10.1128/JVI.00099-09

Parent, L. J., and Gudleski, N. (2011). Beyond plasma membrane targeting: role of the MA domain of Gag in retroviral genome encapsidation. J. Mol. Biol. 410, 553-564. doi: 10.1016/j.jmb.2011.04.072

Parent, L. J., Wilson, C. B., Resh, M. D., and Wills, J. W. (1996). Evidence for a second function of the MA sequence in the Rous sarcoma virus Gag protein. J. Virol. 70, 1016-1026.

Provitera, P., Bouamr, F., Murray, D., Carter, C., and Scarlata, S. (2000). Binding of equine infectious anemia virus matrix protein to membrane bilayers involves multiple interactions. J. Mol. Biol. 296, 887-898. doi: 10.1006/jmbi.1999. 3482

Purohit, P., Dupont, S., Stevenson, M., and Green, M. R. (2001). Sequencespecific interaction between HIV-1 matrix protein and viral genomic RNA revealed by in vitro genetic selection. RNA 7, 576-584. doi: 10.1017/S135583820 1002023

Ramalingam, D., Duclair, S., Datta, S. A., Ellington, A., Rein, A., and Prasad, V. R. (2011). RNA aptamers directed to human immunodeficiency virus type 1 Gag polyprotein bind to the matrix and nucleocapsid domains and inhibit virus production. J. Virol. 85, 305-314 doi: 10.1128/JVI.02626-09

Rao, Z., Belyaev, A. S., Fry, E., Roy, P., Jones, I. M., and Stuart, D. I. (1995). Crystal structure of SIV matrix antigen and implications for virus assembly. Nature 378, 743-747. doi: 10.1038/378743a0

Reil, H., Bukovsky, A. A., Gelderblom, H. R., and Gottlinger, H. G. (1998). Efficient HIV-1 replication can occur in the absence of the viral matrix protein. EMBO J. 17, 2699-2708. doi: 10.1093/emboj/17.9.2699

Rein, A. (1994). Retroviral RNA packaging: a review. Arch. Virol. Suppl. 9, 513-522. doi: 10.1007/978-3-7091-9326-6_49

Rein, A. (2010). Nucleic acid chaperone activity of retroviral Gag proteins. RNA Biol. 6, 700-705. doi: 10.4161/rna.7.6.13685

Reiser, J., Harmison, G., Kluepfel-Stahl, S., Brady, R. O., Karlsson, S., and Schubert, M. (1996). Transduction of nondividing cells using pseudotyped defective hightiter HIV type 1 particles. Proc. Natl. Acad. Sci. U.S.A. 93, 15266-15271. doi: 10.1073/pnas.93.26.15266

Resh, M. D. (2004). A myristoyl switch regulates membrane binding of HIV-1 Gag Proc. Natl. Acad. Sci. U.S.A. 101, 417-418. doi: 10.1073/pnas.0308043101 
Richman, D., Shih, C. K., Lowy, I., Rose, J., Prodanovich, P., Goff, S., et al. (1991). Human immunodeficiency virus type 1 mutants resistant to nonnucleoside inhibitors of reverse transcriptase arise in tissue culture. Proc. Natl. Acad. Sci. U.S.A. 88, 11241-11245. doi: 10.1073/pnas.88.24.11241

Riffel, N., Harlos, K., Iourin, O., Rao, Z., Kingsman, A., Stuart, D., et al. (2002). Atomic resolution structure of the Moloney mu- rine leukemia virus matrix protein and its relationship to other retroviral matrix proteins. Structure 10, 1627-1636. doi: 10.1016/S0969-2126(02)00896-1

Saad, J. S., Ablan, S. D., Ghanam, R. H., Kim, A., Andrews, K., Nagashima, K., et al. (2008). Structure of the myristylated HIV-2 MA protein and the role of phosphatidylinositol-(4,5)-bisphosphate in membrane targeting. J. Mol. Biol. 382, 434-447. doi: 10.1016/j.jmb.2008.07.027

Saad, J. S., Loeliger, E., Luncsford, P., Liriano, M., Tai, J., Kim, A., et al. (2007). Point mutations in the HIV-1 matrix protein turn off the myristyl switch. J. Mol. Biol. 366, 574-585. doi: 10.1016/j.jmb.2006.11.068

Saad, J. S., Miller, J., Tai, J., Kim, A., Ghanam, R. H., and Summers, M. F (2006). Structural basis for targeting HIV-1 Gag proteins to the plasma membrane for virus assembly. Proc. Natl. Acad. Sci. U.S.A. 103, 11364-11369. doi: 10.1073/pnas.0602818103

Sakalian, M., Wills, J. W., and Vogt, V. M. (1994). Efficiency and selectivity of RNA packaging by Rous sarcoma virus Gag deletion mutants. J. Virol. 68, 5969-5981.

Scarlata, S., Ehrlich, L. S., and Carter, C. A. (1998). Membrane-induced alterations in HIV-1 Gag and matrix protein-protein interactions. J. Mol. Biol. 277, 161-169. doi: 10.1006/jmbi.1997.1615

Scheifele, L. Z., Garbitt, R. A., Rhoads, J. D., and Parent, L. J. (2002). Nuclear entry and CRM1-dependent nuclear export of the Rous sarcoma virus Gag polyprotein. Proc. Natl. Acad. Sci. U.S.A. 99, 3944-3949. doi: 10.1073/pnas.062652199

Scholz, I., Still, A., Dhenub, T. C., Coday, K., Webb, M., and Barklis, E. (2008). Analysis of human immunodeficiency virus matrix domain replacements. Virology 371, 322-335. doi: 10.1016/j.virol.2007.10.010

Schultz, A. M., and Oroszlan, S. (1983). In vivo modification of retroviral gag gene-encoded polyproteins by myristic acid. J. Virol. 46, 355-361.

Sen, A., and Todaro, G. J. (1977). The genome-associated, specific RNA binding proteins of avian and mammalian type-C viruses. Cell 10, 91-99. doi: 10.1016/0092-8674(77)90143-X

Spearman, P., Horton, R., Ratner, L., and Kuli-Zade, I. (1997). Membrane binding of human immunodeficiency virus type 1 matrix protein in vivo supports a conformational myristyl switch mechanism. J. Virol. 71, 6582-6592.

Spearman, P., Wang, J. J., Vander Heyden, N., and Ratner, L. (1994). Identification of human immunodeficiency virus type $1 \mathrm{Gag}$ protein domains essential to membrane binding and particle assembly. J. Virol. 68, 3232-3242.

Stansell, E., Apkarian, R., Haubova, S., Diehl, W. E., Tytler, E. M., and Hunter, E. (2007). Basic residues in the Mason-Pfizer monkey virus Gag matrix domain regulate intracellular trafficking and capsid-membrane interactions. J. Virol. 81, 8977-8988. doi: 10.1128/JVI.00657-07

Steeg, C. M., and Vogt, V. M. (1990). RNA-binding properties of the matrix protein (P19gag) of avian sarcoma and leukemia viruses. J. Virol. 64, 847-855.

Swanstrom, R., and Wills, J. W. (1997). "Synthesis, assembly, and processing of viral proteins," in Retroviruses, eds J. Coffin, S. Hughes, and H. Varmus (Cold Spring Harbor, NY: Cold Spring Harbor Laboratory Press), 263-334.

Tang, C., Loeliger, E., Luncsford, P., Kinde, I., Beckett, D., and Summers, M. F. (2004). Entropic switch regulates myristate exposure in the HIV-1 matrix protein. Proc. Natl. Acad. Sci. U.S.A. 101, 517-522. doi: 10.1073/pnas.0305665101

Tedbury, P. R., Ablan, S. D., and Freed, E. O. (2013). Global rescue of defects in HIV-1 envelope glycoprotein incorporation: implications for matrix structure. PLoS Pathog. 9:e1003739. doi: 10.1371/journal.ppat.1003739

Tritel, M., and Resh, M. D. (2000). Kinetic analysis of human immunodeficiency virus type 1 assembly reveals the presence of sequential intermediates. J. Virol. 74, 5845-5855. doi: 10.1128/JVI.74.13.5845-5855.2000
Von Schwedler, U., Kornbluth, R. S., and Trono, D. (1994). The nuclear localization signal of the matrix protein of human immunodeficiency virus type 1 allows the establishment of infection in macrophages and quiescent T lymphocytes. Proc. Natl. Acad. Sci. U.S.A. 91, 6992-6996. doi: 10.1073/pnas.91. 15.6992

Wang, C. T., Zhang, Y., McDermott, J., and Barklis, E. (1993). Conditional infectivity of a human immunodeficiency virus matrix domain deletion mutant. J. Virol. 67, 7067-7076.

Wang, H., Norris, K. M., and Mansky, L. M. (2003). Involvement of the matrix and nucleocapsid domains of the bovine leukemia virus Gag polyprotein precursor in viral RNA packaging. J. Virol. 77, 9431-9438. doi: 10.1128/JVI.77.17.94319438.2003

Wilk, T., Pfeiffer, T., and Bosch, V. (1992). Retained in vitro infectivity and cytopathogenicity of HIV-1 despite truncation of the C-terminal tail of the env gene product. Virology 189, 167-177. doi: 10.1016/0042-6822(92) 90692-I

Wyma, D. J., Kotov, A., and Aiken, C. (2000). Evidence for a stable interaction of gp41 with Pr55(Gag) in immature human immunodeficiency virus type 1 particles. J. Virol. 74, 9381-9387. doi: 10.1128/JVI.74.20.93819387.2000

Wyma, D. J., Jiang, J., Shi, J., Zhou, J., Lineberger, J. E., Miller, M. D., etal. (2004). Coupling of human immunodeficiency virus type 1 fusion to virion maturation: a novel role of the gp41 cytoplasmic tail. J. Virol. 78, 3429-3435. doi: 10.1128/JVI.78.7.34293435.2004

Yu, X., Yuan, X., Matsuda, Z., Lee, T. H., and Essex, M. (1992). The matrix protein of human immunodeficiency virus type 1 is required for incorporation of viral envelope protein into mature virions. J. Virol. 66, 4966-4971.

Zavada, J. (1982). The pseudotypic paradox. J. Gen. Virol. 63, 15-24. doi: 10.1099/0022-1317-63-1-15

Zhang, J. H., Chung, T. D. Y., and Oldenburg, K. R. (1999). A simple statistical parameter for use in evaluation and validation of high throughput screening assays. J. Biomol. Screen. 4, 67-73. doi: 10.1177/10870571990 0400206

Zhou, J., McAllen, J. K., Tailor, Y., and Summers, M. F. (2005). High affinity nucleocapsid protein binding to the muPsi RNA packaging signal of Rous sarcoma virus. J. Mol. Biol. 349, 976-988. doi: 10.1016/j.jmb.2005. 04.046

Zhou, W., Parent, L. J., Wills, J. W., and Resh, M . D. (1994). Identification of a membrane-binding domain within the amino-terminal region of human immunodeficiency virus type $1 \mathrm{Gag}$ protein which interacts with acidic phospholipids. J. Virol. 68, 2556-2569.

Conflict of Interest Statement: The authors declare that the research was conducted in the absence of any commercial or financial relationships that could be construed as a potential conflict of interest.

Received: 18 February 2014; accepted: 08 May 2014; published online: 28 May 2014. Citation: Alfadhli A and Barklis E (2014) The roles of lipids and nucleic acids in HIV-1 assembly. Front. Microbiol. 5:253. doi: 10.3389/fmicb.2014.00253

This article was submitted to Virology, a section of the journal Frontiers in Microbiology. Copyright (c) 2014 Alfadhli and Barklis. This is an open-access article distributed under the terms of the Creative commons attribution license (CC BY). The use, distribution or reproduction in other forums is permitted, provided the original author(s) or licensor are credited and that the original publication in this journal is cited, in accordance with accepted academic practice. No use, distribution or reproduction is permitted which does not comply with these terms. 